\title{
Intracranial suppuration complicating sinusitis among children: an epidemiological and clinical study
}

\author{
Clinical article
}

\author{
Joseph H. Piatt JR., M.D. \\ Division of Neurosurgery, Nemours/Alfred I. duPont Hospital for Children, Wilmington, Delaware; and \\ Department of Neurological Surgery, Thomas Jefferson University, Philadelphia, Pennsylvania
}

Object. Intracranial abscess is a very infrequent complication of sinusitis among children. Case series, mostly small and focusing on surgical treatment, have appeared in the literature, but there has been no study on the epidemiology of this condition, nor has there been any large-scale study on the intensity of therapy or outcomes.

Methods. Data were drawn from the Kids' Inpatient Databases for 1997, 2000, 2003, and 2006 and the National Inpatient Sample for 2001. Cases were defined by the conjunction between the diagnostic codes for intracranial abscess and those for acute or chronic sinusitis or mastoiditis.

Results. Eight hundred forty-seven hospital admissions were captured. Over the 10 years of the study, admission rates ranged between 2.74 and 4.38 per million children per year. Boys were affected much more commonly than girls. Black children were affected out of proportion to their presence in the population. The overall incidence seemed to peak in early adolescence. Sinogenic cases had a marked seasonal pattern peaking in winter, but no seasonal variation was seen for otogenic cases. Asthma comorbidity was more prevalent among sinogenic cases. The mortality rate was $2 \%$, and death occurred only among sinogenic cases. Moreover, sinogenic cases tended to require more intensive therapy, as measured by the number of procedures, and there was a trend toward less favorable discharge dispositions. Older patients and black patients were less likely to be discharged directly to home. At least a quarter of the cases were managed without neurosurgical intervention. White patients were treated without neurosurgery more often than others.

Conclusions. Analysis of administrative data sets has yielded a descriptive picture of intracranial abscess complicating sinusitis among children, but the very low incidence of this condition impedes prospective clinical research directed at practical management issues. (DOI: 10.3171/2011.3.PEDS10504)

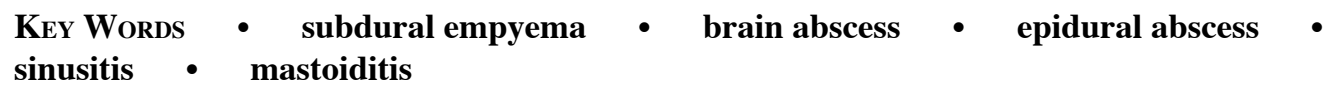

$\mathrm{E}$ PIDURAL abscess, subdural empyema, and cerebral abscess are infrequent but threatening complications of sinusitis. These conditions have not been the object of any epidemiological studies. Because individual surgeons accumulate limited personal experience with this disorder and because there is wide variation from case to case in terms of the volume and distribution of intracranial pus, many practical management decisions are left to clinical judgment largely unsupported by useful evidence. Evolving patterns of antibiotic sensitivity among offending bacteria add additional uncertainty. The current study

Abbreviations used in this paper: HCUP = Healthcare Cost and Utilization Project; ICD-9-CM = International Classification of Diseases, 9th Revision, Clinical Modification; KID = Kids' Inpatient Database; LOS = length of stay; NIS = Nationwide Inpatient Sample. was undertaken to assess the population-based burden of this condition, the spectrum of its severity, and the intensity of neurosurgical care required for its management. Such data may provide guidance in the design of prospective, cooperative, clinical trials.

\section{Methods}

The data for this study were derived from the HCUP of the Agency for Healthcare Research and Quality. The KID is a compilation of deidentified discharge data from a stratified sample of all hospital discharges of patients in the pediatric age range from community, nonrehabilitation hospitals in the US. Each KID includes roughly $10 \%$ of all discharges of uncomplicated in-hospital live births and roughly $80 \%$ of discharges of complicated births and other pediatric cases from each sampled hospital. Weights 
are provided for the discharges to permit estimation of incidences in the entire universe of American Hospital Association institutions. The NIS is a compilation of data from a roughly $20 \%$ sample of hospital discharges of patients of all ages. Likewise, weights are provided for estimation of national incidences. This study used the KIDs for 1997, 2000, 2003, and 2006 and the NIS for 2001 in various combinations as specified. Population data for the calculation of national admission rates were taken from the US Census. ${ }^{55}$

Cases were identified on the basis of ICD-9-CM codes. Sinogenic intracranial abscesses were defined by the coincident recording of codes 324.0 or 324.9 for intracranial abscess and codes 461 or 473 (including 4- and 5-digit subcodes) for acute and chronic sinusitis. Otogenic intracranial abscesses were defined by the coincident codes of 324.0 or 324.9 and 383 (including 4- and 5-digit subcodes) for mastoiditis. Cases coded for both sinusitis and mastoiditis were included arbitrarily in the sinogenic group. Coding for otitis was discounted in the definition of otogenic cases because of its high and nonspecific prevalence as an intercurrent illness in the pediatric population.

The HCUP utilizes ICD-9-CM codes for surgical procedures. Neurosurgical procedures were defined by codes 01.0 through 02.92. Requirement for mechanical ventilation was defined by codes 96.7 through 96.72 .

Epidemiological analysis was conducted using the KIDs for 1997, 2000, 2003, and 2006. The KID for 1997 included discharges of patients from birth through 17 years of age. The later KIDs included cases from birth through 20 years of age. Discharges were weighted to estimate national incidences and to perform comparisons with national census data. For some comparisons within the KID data collection process, weighted discharges of uncomplicated in-hospital births were used as control groups. Because of small numbers of otogenic cases, epidemiological analysis was limited to sinogenic intracranial abscesses. To preserve the deidentification of its data, the HCUP requires investigators not to report tabulated data with values $<10$ in a cell.

The data sets were manipulated and analyzed using SPSS 17.0. Epidemiological analysis was based on national estimates from weighted discharges. Clinical analysis was based on unweighted discharge data. In the epidemiological analysis, statistical hypothesis testing was not undertaken for estimates of population-based incidences because the HCUP has not developed code for SPSS for the calculation of variances and confidence intervals. All statistical tests in the clinical analysis were 2-sided except as indicated. Multivariate analysis was performed via logistic regression using the forward likelihood ratio method with variables demonstrated to have significant associations in univariate analysis. The $\mathrm{p}$ values are presented.

This research was classified as exempt from review by the Nemours Delaware Institutional Review Board.

\section{Results \\ Epidemiological Factors \\ Estimated annual rates of admission for sinogenic in- tracranial abscess are presented in Table 1 for all 4 years}

of available KID data. These estimates were calculated from the discharge weights provided in the KID and from data from the US Census. The rates of admission ranged from 2.74 to 4.38 per million children per year. Nine percent of weighted admissions for sinogenic intracranial abscess ended in transfers to other acute care facilities. In principle, an unknown fraction of these transfers may have been counted twice-both at the hospital of original admission and at the receiving hospital following transfer. Double counting may therefore have inflated estimated admission rates to a small degree in relation to actual incidences of the condition.

Patient sex was a clear risk factor for the development of sinogenic intracranial abscesses. The male/female ratio varied between 2.0:1 and 3.8:1 in the 4 years of KID data.

Race was a clear risk factor as well. Black children were disproportionately affected. Relative risk calculations based on census data for racial groups in the US population for 2000, 2003, and 2006 are presented in Table 2. Note that appropriate control census data were not readily accessible for 1997.

Two metrics of economic status are available within the KID. Based on home zip code, the KID assigns each discharge to a quartile of the distribution of all zip codes in the US ranked by median household income. Weighted cases of sinogenic intracranial abscesses were distributed almost perfectly uniformly among the 4 quartiles (data not shown). The KID also identifies primary and secondary payers for each discharge. As a control group for weighted cases of sinogenic abscess, weighted discharges after uncomplicated live births were analyzed. The distribution of weighted discharges among the categories of primary payer was very similar for sinogenic intracranial abscesses and uncomplicated live births for all 4 years of available KID data (data not shown). There was no evidence that economic status was a risk factor for the development of sinogenic intracranial abscess.

\section{Clinical Data}

Eight hundred forty-seven admissions for intracranial abscess associated with sinusitis were analyzed. Six hundred ninety-five were classified as sinogenic and 152 as otogenic, as defined above. Patient age on admission for the entire study group is presented in Fig. 1. The modal age was 12 years, and generally the age-specific incidence seemed to peak in early adolescence. There was a clear seasonal pattern in the incidence of sinogenic intracranial abscess, but no pattern was obvious for oto-

\section{TABLE 1: Estimated annual rates of hospital admission for sinogenic intracranial abscesses*}

\begin{tabular}{cc}
\hline Year & Admissions for Sinogenic Intracranial Abscesses \\
\hline $1997 \dagger$ & 3.00 \\
2000 & 2.74 \\
2003 & 4.38 \\
2006 & 4.04 \\
\hline * Per 106 children per year. & \\
$\dagger$ & \\
& Through 17 years of age. All other estimates through 20 years of age.
\end{tabular}


TABLE 2: Relative risk of sinogenic intracranial abscess by racial group

\begin{tabular}{llll}
\hline Group & 2000 & 2003 & 2006 \\
\hline white & 0.547 & 0.475 & 0.555 \\
black & 2.37 & 2.74 & 2.16 \\
Hispanic & 0.806 & 0.898 & 0.927 \\
other & 1.7 & 1.47 & 1.68 \\
\hline
\end{tabular}

genic cases (Fig. 2). Other demographic and clinical data are presented in Table 3. Patients with sinogenic infection tended to be older. Male predominance was more pronounced for sinogenic admissions. Black children constituted a much larger fraction of sinogenic admissions than otogenic. Sinogenic admissions tended to entail more coded procedures than otogenic, and this trend was even more pronounced for neurosurgical procedures. Duration of stay was similar for sinogenic and otogenic admissions. The overall in-hospital mortality rate was $2 \%$ (15 of 847 patients). There were no deaths among the otogenic admissions, and a larger fraction of otogenic admissions ended in discharge directly to home.

Because of the physiological and immunological continuity of the nasal airway, the nasal sinuses, and the tracheobronchial tree, the prevalence of asthma in the study group was analyzed. ${ }^{2}$ Among the 847 admissions for intracranial abscess associated with sinusitis, 62 records $(7.3 \%)$ were coded for asthma as well. Sinogenic and otogenic abscesses were associated with asthma in $8.2 \%$ and $3.3 \%$ of admissions, respectively ( $\mathrm{p}=0.039$, Fisher exact test). The prevalence of asthma among black children was higher

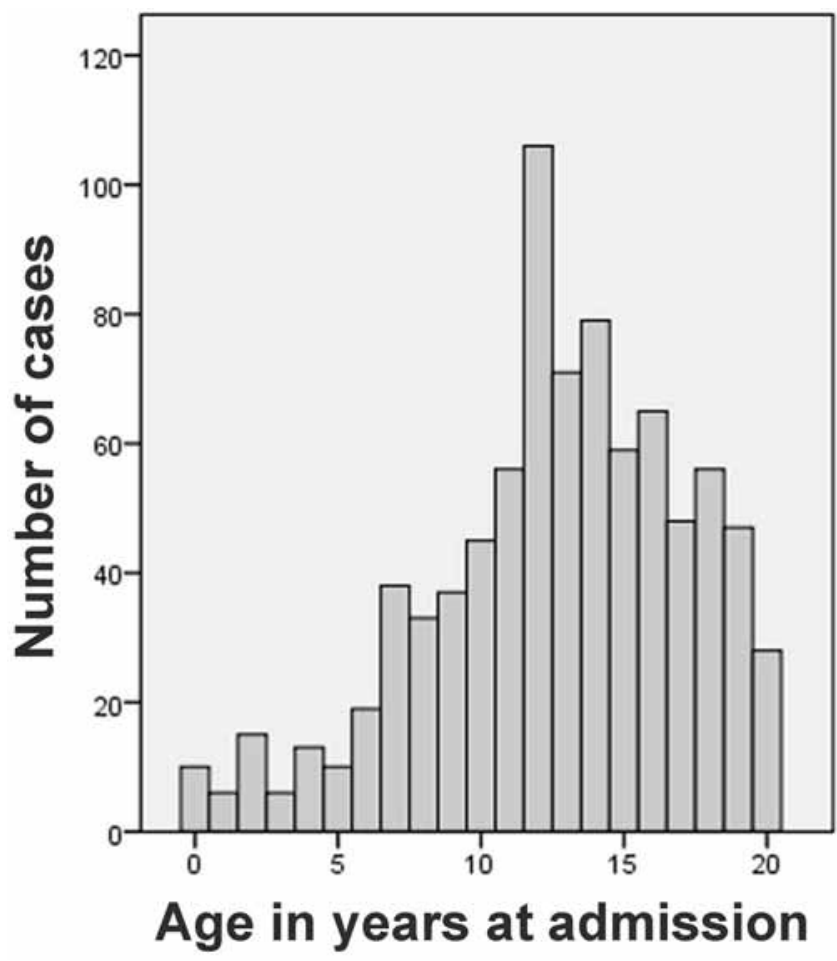

Fig. 1. Bar graph demonstrating the distribution of ages for 847 admissions for sinogenic and otogenic intracranial abscesses. than in other racial groups, but this trend did not reach significance (data not shown; $\mathrm{p}=0.124$, Pearson chi-square). To place these observations in some context, from the 2000 KID, the prevalences of asthma among admissions for appendicitis and femur fracture were calculated to be $3.4 \%$ and $3.3 \%$, respectively. The prevalence of asthma among admissions for sinogenic intracranial abscess in the 2000 KID was $8.3 \%$. Assuming a background asthma prevalence of $3.3 \%$, which also happened to be the prevalence of asthma among cases of otogenic intracranial abscess in the study group, the prevalence of asthma among admissions for sinogenic intracranial abscess in the $2000 \mathrm{KID}$ is markedly elevated ( $\mathrm{p}<0.0005$, binomial test, 1 -tailed). Thus, asthma seems to be a risk factor for the development of sinogenic, but not otogenic, intracranial abscess.

The number of neurosurgical procedures required during each admission is presented in Fig. 3. One-third of admissions (281 [33\%] of 847) involved no neurosurgical procedure. To estimate the fraction of actual cases that involved no neurosurgical procedure, some allowance must be made for transfers and the possibility of double counting transferred patients: 80 admissions ended in transfer to another short-term facility, and 59 of these admissions involved no neurosurgical procedure. If all 59 of these transfers were necessitated by the absence of neurosurgical services at the sending facility, if all 59 patients underwent neurosurgical procedures at the receiving facility, and if none of the 59 transfers happened to be double-counted as admissions at the receiving institutions in the KID data sets, a lower limit on the fraction of cases not requiring neurosurgical intervention might be estimated by eliminating these cases from the numerator: $(281-59) / 847=26 \%$.

If, however, some of the transfers were double counted as admissions at the receiving institutions, then these patients were represented twice in the denominator, as well in the numerator. Subtracting such cases from the denominator increases the value of the fraction, so $26 \%$ is a lower limit to the possible range of values for the fraction of cases not requiring neurosurgical intervention. Thus, at least a quarter of cases represented in the study group seem to have been treated without neurosurgical procedures.

Given that such a significant minority of cases seemed to have been managed without neurosurgical intervention, further characterization of these cases was attempted. For this analysis, admissions that ended in transfer to another acute care facility were filtered, because in theses cases the performance of a neurosurgical procedure was most likely determined by the availability of services at the initial admitting hospital rather than by any feature of the case itself. In a binary comparison, nonneurosurgical management was strongly associated with white race $(p=0.016$, Fisher exact test). There was no association with the origin of infection ( $p=0.299$, Fisher exact test), age $(p=0.839$, Mann-Whitney U-test), sex ( $p=0.859$, Fisher exact test), payer ( $\mathrm{p}=0.404$, Pearson chi-square), or asthma comorbidity $(p=0.450$, Fisher exact test). There was a weak trend associating nonneurosurgical management with the highest quartile median income of home zip code $(p=0.192$, Fisher exact test).

Mechanical ventilation was recorded in 75 (8.9\%) of 847 admissions. Requirement for mechanical ventilation 


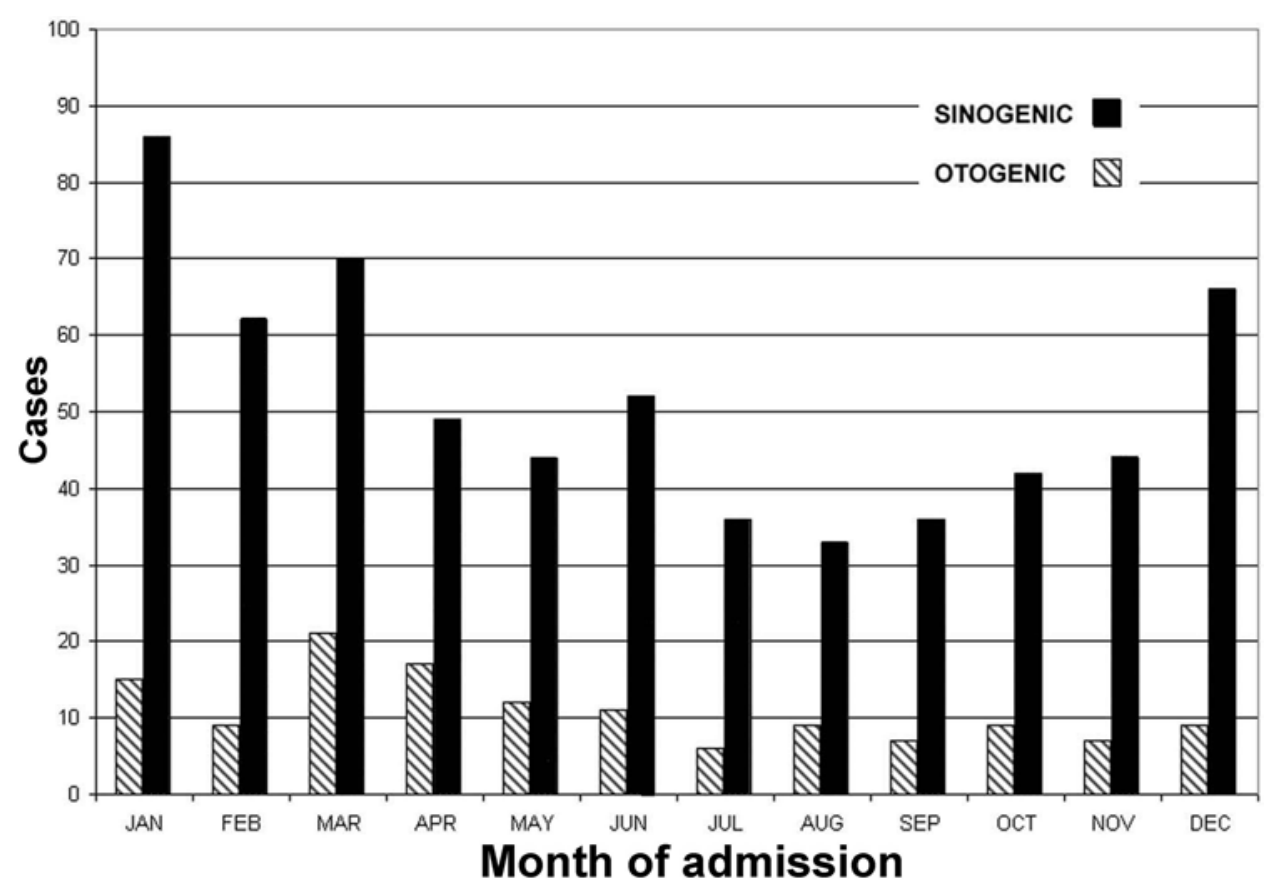

FIG. 2. Bar graph showing seasonal variation in 847 admissions for sinogenic and otogenic intracranial abscesses.

was strongly associated with the number of neurosurgical procedures ( $\mathrm{p}<0.0005$, Mann-Whitney U-test).

The only outcome metrics available in the KID and NIS data sets are discharge disposition and LOS. Inspection of the data suggested that many admissions with the shortest LOSs ended in transfers to other acute care hospitals, probably for services such as neurosurgery that were not available at the sending hospital. To work around the confounding effects of early transfers, a "favorable" disposition was defined as a discharge to home, without or with home health services. All other dispositions were "unfavorable." Early transfers exerted a similar confounding effect on LOS; thus, for purposes of outcome analysis, discharges with LOSs in the fourth quartile ( $>15$ days) were defined as "long."

Data regarding discharge disposition are presented in Table 4. Patients with unfavorable dispositions were slightly older than those with favorable dispositions. Discharge disposition was unrelated to patient sex. Black children experienced slightly higher rates of unfavorable disposition. Payer and median income of home zip code were unrelated to discharge disposition. Asthma comorbidity was unrelated to disposition. Calendar year of admission was unrelated to disposition (data not shown; $p=0.081$, Somers' D test). Unfavorable disposition was strongly associated with larger numbers of neurosurgical procedures and with the requirement for mechanical ventilation. On multivariate analysis by multiple logistic regression, the number of neurosurgical procedures $(\mathrm{p}<0.0005)$, requirement for mechanical ventilation ( $\mathrm{p}<0.0005)$, and patient race $(p=0.033)$ retained significance, whereas patient age and sino- or otogenic etiology did not. Excluding the number of neurosurgical procedures and the requirement for mechanical ventilation, which were characteristics of the hospital course, patient age $(p=0.015)$ and race $(p=0.032)$ retained significance.
Because transfer to another short-term facility may reflect barriers to access to definitive care, this disposition was analyzed further. There was no association between transfer to another short-term facility and race $(\mathrm{p}=$ 0.716 ), payer ( $p=0.456$ ), or median income of home zip code $(\mathrm{p}=0.073)$, according to Pearson chi-square testing.

Data regarding LOS are presented in Table 5. A long LOS was unrelated to patient age or sex, but white children were underrepresented among discharges with a long LOS. Medicaid was overrepresented, and commercial payers were underrepresented among discharges with a long LOS. Race and payer were strongly linked, given that commercial insurance is much more prevalent among white children than other groups (data not shown; $\mathrm{p}<0.0005$, Pearson chi-square). The median income of home zip code was unrelated to LOS, as were asthma comorbidity and calendar year of admission (data not shown; $p=0.1$, Somers' $D$ test). Not surprisingly, a long LOS was associated with larger numbers of neurosurgical procedures and the requirement for mechanical ventilation. On multivariate analysis the requirement for mechanical ventilation $(\mathrm{p}<0.0005)$, number of neurosurgical procedures $(\mathrm{p}<0.0005)$, and payer $(\mathrm{p}<$ 0.0005 ) retained significance, whereas race and sino- or otogenic etiology did not. Excluding the number of neurosurgical procedures and the requirement for mechanical ventilation, only payer $(\mathrm{p}<0.0005)$ retained significance.

The small number of deaths, 15 cases among 847, does not permit precise statistical characterization. As noted previously, there were no deaths among the otogenic cases. There was no association with patient sex ( $p$ $=0.293$, Pearson chi-square $)$, race $(\mathrm{p}=0.671)$, payer $(\mathrm{p}=$ $0.305)$, median income of home zip code $(\mathrm{p}=0.661)$, or asthma comorbidity $(p=0.272)$. In dichotomized analyses there was no association between death and white race $(\mathrm{p}=1.00$, Fisher exact test) or highest quartile median income of home zip code $(\mathrm{p}=0.541)$. The median age 
TABLE 3: Demographic and clinical features of captured cases of sinogenic and otogenic intracranial abscesses

\begin{tabular}{|c|c|c|c|}
\hline Parameter & Sinogenic & Otogenic & $p$ Value \\
\hline total no. cases & 695 & 152 & \\
\hline age in yrs & & & $<0.0005^{*}$ \\
\hline median & 13 & 10 & \\
\hline interquartile range & $11-16$ & $6-15$ & \\
\hline range & $0-20$ & $0-20$ & \\
\hline$M / F$ & $2.92: 1$ & $1.58: 1$ & $0.001 \dagger$ \\
\hline race & & & $<0.0005 \ddagger$ \\
\hline white & 231 & 71 & \\
\hline black & 169 & 11 & \\
\hline Hispanic & 91 & 31 & \\
\hline other & 45 & 12 & \\
\hline total procedures & & & $0.094^{*}$ \\
\hline median & 4 & 4 & \\
\hline interquartile range & $2-6$ & $2-6$ & \\
\hline range & $0-21$ & $0-18$ & \\
\hline neurosurgical procedures & & & $0.038^{*}$ \\
\hline median & 1 & 1 & \\
\hline interquartile range & $0-1$ & $0-1$ & \\
\hline range & $0-13$ & $0-6$ & \\
\hline LOS in days & & & $0.813^{*}$ \\
\hline median & 9 & 9 & \\
\hline interquartile range & $6-15$ & $6-15$ & \\
\hline range & $0-72$ & $0-67$ & \\
\hline disposition & & & $0.061 \ddagger$ \\
\hline home & 335 & 91 & \\
\hline short-term facilities & 65 & 15 & \\
\hline other transfers & 61 & $\S$ & \\
\hline home health & 216 & 36 & \\
\hline dead & 15 & $\S$ & \\
\hline other & $\S$ & $\S$ & \\
\hline
\end{tabular}

* Mann-Whitney U-test.

$\dagger$ Fisher exact test.

$\ddagger$ Pearson chi-square test.

$\S$ Fewer than 10 observations.

of patients who died was 14 years compared with 13 years among survivors, but this difference was not significant ( $p=0.104$, Mann-Whitney U-test). The median LOS for admissions that ended in death was shorter at 4 days than the median LOS for admissions of survivors, which was 9 days ( $p=0.037$, Mann-Whitney U-test). There was no significant difference in numbers of neurosurgical procedures $(p=0.206$, Mann-Whitney U-test).

\section{Discussion}

The limitations of administrative databases for purposes of clinical research are widely recognized and are exemplified in the current study. The ICD-9-CM codes used for case definition in this study do not distinguish among several very different clinical entities: epidural ab-

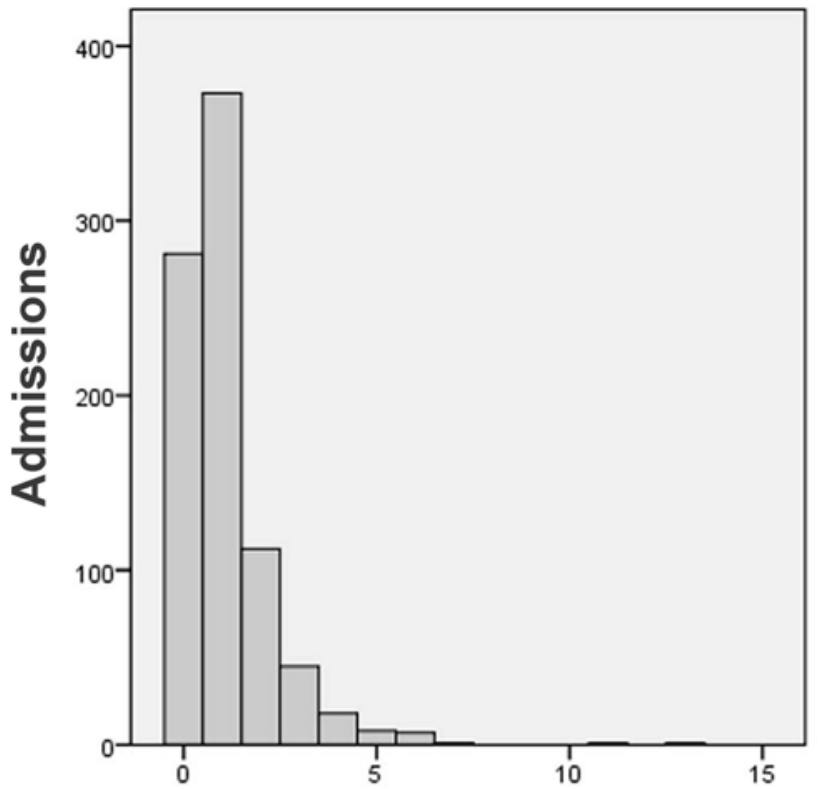

Number of neurosurgical procedures

FIG. 3. Bar graph indicating the distribution of numbers of neurosurgical procedures for 847 admissions for sinogenic and otogenic intracranial abscesses.

scess, subdural empyema, brain abscess, and the so-called subdural effusion that complicates meningitis in infancy. The restrictive definition of "otogenic" cases, based on codes for mastoiditis, may have passed over abscesses that developed from otitis without mastoiditis. There were no data describing the severity of the illness at presentation. There were no bacteriological data. The codes for neurosurgical procedures from the ICD-9-CM are notoriously nonspecific: Salient to the surgical management of intracranial abscesses is the blindness of ICD-9-CM coding to the distinction between bur holes and craniotomies. There were no data describing functional outcomes.

Nevertheless, the current study of intracranial abscess complicating sinusitis presents a qualitative picture of this clinical entity, some details of which have not been appreciated before. The incidence of this condition seems to peak in early adolescence. It affects boys much more commonly than girls, and it affects black children out of proportion to their presence in the general population. Sinogenic cases have a marked seasonal pattern, peaking in winter, although no such pattern is evident for otogenic cases. Similarly, sinogenic cases have an association with asthma not shared with otogenic cases. Sinogenic cases tend to require more intensive therapy, as measured by numbers of procedures, and there is a trend toward less favorable discharge dispositions. White patients are treated without neurosurgical intervention more frequently. Older patients and black patients are less likely to be discharged directly to home. Patients with the longest hospital admissions tend to have Medicaid as their primary payer.

Descriptions of various epidemiological and clinical features of intracranial suppuration complicating sinusitis among children can be found in numerous small, insti- 
TABLE 4: Discharge disposition

\begin{tabular}{|c|c|c|c|}
\hline Parameter & Favorable & Unfavorable & p Value \\
\hline age in yrs & & & $0.001^{*}$ \\
\hline median & 13 & 15 & \\
\hline interquartile range & $10-16$ & $12-17$ & \\
\hline range & $0-20$ & $0-20$ & \\
\hline $\mathrm{M} / \mathrm{F}$ & $2.53: 1$ & $3.47: 1$ & $0.306 \dagger$ \\
\hline race & & & $0.020 \ddagger$ \\
\hline white & 279 & 21 & \\
\hline black & 152 & 28 & \\
\hline Hispanic & 110 & 10 & \\
\hline other & 50 & $\S$ & \\
\hline payer & & & $0.440 \ddagger$ \\
\hline Medicaid & 258 & 30 & \\
\hline commercial & 407 & 43 & \\
\hline self & 46 & $\S$ & \\
\hline no charge & $\S$ & $\S$ & \\
\hline other & 41 & $\S$ & \\
\hline asthma & & & $0.269 \dagger$ \\
\hline absent & 705 & 76 & \\
\hline present & 53 & $\S$ & \\
\hline neurosurgical procedures & & & $<0.005^{\star}$ \\
\hline median & 1 & 1 & \\
\hline interquartile range & $0-1$ & $1-3$ & \\
\hline range & $0-13$ & $0-7$ & \\
\hline $\begin{array}{l}\text { * Mann-Whitney U-test. } \\
\dagger \text { Fisher exact test. } \\
\text { † Pearson chi-square test } \\
\S \text { Fewer than } 10 \text { observati }\end{array}$ & & & \\
\hline
\end{tabular}

tution-based case series. ${ }^{1,3-23,25-29,31,34-45,48-54,56-60}$ Many of these reports are inhomogeneous with respect to etiology, including infectious collections related to community-acquired meningitis, congenital heart disease, trauma, and previous surgery. Many reports limited to complications of sinusitis include orbital cellulitis, dural sinus thrombophlebitis, and meningitis, which were not considered in the current study. Data in the present study confirm the predominance of male patients observed in previous work and the predominant affliction of adolescents and young adults. $3,14,16,20,31,34,42,45,49$ Contemporary literature has described low mortality rates as well, although not generally as low as in the current study. ${ }^{13,15,29,31,37,42,44,53}$

The disproportionate representation of black children among patients with intracranial suppurative complications of sinusitis has received comment as well. ${ }^{20}$ Notable are the substantial contributions to the literature on this topic from centers in Africa. ${ }^{16,30,31,38,46,47}$ From the era before CT, Glasauer and associates ${ }^{16}$ documented 44 cases of subdural empyema from what was in 1978 the University of Rhodesia. Twenty-four patients appeared to have sinogenic infections. A peak incidence in the 2nd decade of life was noted in comparison with the age distribution of the region's population of the region. The authors commented on the higher ratio of subdural to intracerebral
TABLE 5: Length of stay*

\begin{tabular}{|c|c|c|c|}
\hline Parameter & Not Long & Long & p Value \\
\hline age in yrs & & & $0.118 \dagger$ \\
\hline median & 13 & 13 & \\
\hline interquartile range & $10-16$ & $11-16$ & \\
\hline range & $0-20$ & $0-20$ & \\
\hline $\mathrm{M} / \mathrm{F}$ & $2.52: 1$ & $2.78: 1$ & $0.656 \ddagger$ \\
\hline race & & & $0.007 \S$ \\
\hline white & 243 & 59 & \\
\hline black & 123 & 57 & \\
\hline Hispanic & 83 & 39 & \\
\hline other & 40 & 17 & \\
\hline payer & & & $<0.0005 \S$ \\
\hline Medicaid & 196 & 92 & \\
\hline commercial & 375 & 78 & \\
\hline self & 38 & 18 & \\
\hline no charge & Ø & П & \\
\hline other & 26 & 18 & \\
\hline asthma & & & $0.762 \ddagger$ \\
\hline absent & 591 & 194 & \\
\hline present & 48 & 14 & \\
\hline neurosurgical procedures & & & $<0.0005 \dagger$ \\
\hline median & 1 & 1 & \\
\hline interquartile range & $0-1$ & $1-3$ & \\
\hline range & $0-5$ & $0-13$ & \\
\hline \multicolumn{4}{|c|}{$\begin{array}{l}\text { * "Long" LOS was defined as > } \\
\text { for LOS. } \\
\dagger \text { Mann-Whitney U-test. } \\
\ddagger \text { Fisher exact test. } \\
\S \text { Pearson chi-square test. } \\
\text { ๆ Fewer than } 10 \text { observations. }\end{array}$} \\
\hline
\end{tabular}

abscesses in Africa compared with those in Western centers. In 1999 Singh and associates ${ }^{47}$ from the Department of Otolaryngology, University of Natal, South Africa, described 219 patients, of whom 197 had various intracranial abscesses and 22 had meningitis. As in the current study, the modal age was in the 11- to 15 -year range. Orbital infection was present in $41 \%$ of cases. Despite a policy of draining pus within 12 hours of patient admission, the mortality rates were $45 \%$ for meningitis, $19 \%$ for brain abscess, and $11 \%$ for subdural empyema. There were no deaths among patients with isolated epidural abscesses. Survival correlated with level of responsiveness at presentation. From the Department of Neurosurgery at the same institution, Nathoo and associates ${ }^{32}$ reported 699 cases of supratentorial subdural empyema. Four hundred sixty-nine cases were sinogenic, and 64 were otogenic. As in other series, male patients in their 2nd and 3rd decades predominated, and there was a peak disease incidence in winter that did not attain significance in the authors' statistical analysis. The mortality rate was $12.2 \%$. Over the 15 years of this study, the institutional practice evolved from multiple bur holes to large osteoplastic craniotomies, which the authors believed gave much better ac- 
cess to tenacious pus more widely distributed than preoperative imaging typically suggested. In a companion paper Nathoo and associates ${ }^{31}$ presented 82 patients with epidural abscesses, 69 of whom had sinogenic etiologies. There was only 1 death in that series. Eleven patients were treated without draining intracranial pus; 6 were cared for as outpatients. The authors concluded that epidural abscess is a condition that ought to be manageable without morbidity or death. ${ }^{31}$

English-language reports from India have described subdural empyema in childhood to be predominantly otogenic in origin and very often infratentorial in location. 5,27,39,43,56,61 Whether this interesting regional pattern of disease reflects phenotypic variation or environmental factors has not been explored.

The only previous population-based study of sinogenic intracranial abscesses was conducted in Scotland. Nunez ${ }^{33}$ undertook a retrospective search of Scottish Health Service records for the years 1976-1985 supplemented by searches of departmental records at the 4 Scottish neurosurgical centers. Twenty-three cases were reviewed; 12 patients were in the first 2 decades of life. The paper is not clear about the completeness of the search, and the author did not estimate regional annual incidences. Aside from this report, there seem to have been no previous attempts to estimate the incidence of intracranial abscess complicating sinusitis. The admission rate for such cases in the US during the period of the current study was low, between 2.74 and 4.38 cases per million children per year, and the actual incidence may be slightly lower. During this decade the US population in the 0-20 years of age range was roughly 85 million, and there were very roughly 200 full-time pediatric neurosurgeons. Even if all cases had reached pediatric neurosurgeons, each surgeon would have been consulted for $<2$ cases per year.

The substantial body of retrospective literature on this topic has articulated, but left unresolved, a number of practical questions. In the office management of sinusitis, are there measures that can reduce the risk of its very uncommon intracranial complications? ${ }^{24}$ Are there anatomical, physiological, or immunological factors that place patients with sinusitis at particular risk? Can guidelines be developed for early imaging detection of intracranial suppuration before the appearance of overt neurological symptoms and signs? What is the optimal sequence and timing of drainage procedures? In which cases, if any, can draining be effectively accomplished via bur holes, and which patients require craniotomy? In view of the very low annual incidence estimated in the current study, prospective clinical research must cast a wide net for a long period of time to capture cases in numbers sufficient to establish an evidentiary basis for answers.

\section{Conclusions}

The analysis of administrative data sets has yielded a descriptive picture of intracranial abscess complicating sinusitis among children, but the very low incidence of this condition impedes prospective clinical research directed at practical management issues.

\section{Disclosure}

The author reports no conflict of interest concerning the materials or methods used in this study or the findings specified in this paper.

\section{References}

1. Adame N, Hedlund G, Byington CL: Sinogenic intracranial empyema in children. Pediatrics 116:e461-e467, 2005

2. Bachert C, Vignola AM, Gevaert P, Leynaert B, Van Cauwenberge P, Bousquet J: Allergic rhinitis, rhinosinusitis, and asthma: one airway disease. Immunol Allergy Clin North Am 24:19-43, 2004

3. Bair-Merritt MH, Shah SS, Zaoutis TE, Bell LM, Feudtner C: Suppurative intracranial complications of sinusitis in previously healthy children. Pediatr Infect Dis J 24:384-386, 2005

4. Bambakidis NC, Cohen AR: Intracranial complications of frontal sinusitis in children: Pott's puffy tumor revisited. Pediatr Neurosurg 35:82-89, 2001

5. Banerjee AD, Pandey P, Devi BI, Sampath S, Chandramouli BA: Pediatric supratentorial subdural empyemas: a retrospective analysis of 65 cases. Pediatr Neurosurg 45:11-18, 2009

6. Bayonne E, Kania R, Tran P, Huy B, Herman P: Intracranial complications of rhinosinusitis. A review, typical imaging data and algorithm of management. Rhinology 47:59-65, 2009

7. Betz CS, Issing W, Matschke J, Kremer A, Uhl E, Leunig A: Complications of acute frontal sinusitis: a retrospective study. Eur Arch Otorhinolaryngol 265:63-72, 2008

8. Brook I: Aerobic and anaerobic bacteriology of intracranial abscesses. Pediatr Neurol 8:210-214, 1992

9. Brook I: Bacteriology of intracranial abscess in children. J Neurosurg 54:484-488, 1981

10. Dill SR, Cobbs CG, McDonald CK: Subdural empyema: analysis of 32 cases and review. Clin Infect Dis 20:372-386, 1995

11. Eufinger H, Machtens E: Purulent pansinusitis, orbital cellulitis and rhinogenic intracranial complications. J Maxillofac Surg 29:111-117, 2001

12. Gallagher RM, Gross CW, Phillips CD: Suppurative intracranial complications of sinusitis. Laryngoscope 108:16351642,1998

13. Germiller JA, Monin DL, Sparano AM, Tom LW: Intracranial complications of sinusitis in children and adolescents and their outcomes. Arch Otolaryngol Head Neck Surg 132: 969-976, 2006

14. Giannoni C, Sulek M, Friedman EM: Intracranial complications of sinusitis: a pediatric series. Am J Rhinol 12:173-178, 1998

15. Giannoni CM, Stewart MG, Alford EL: Intracranial complications of sinusitis. Laryngoscope 107:863-867, 1997

16. Glasauer FE, Coots D, Levy LF, Auchterlonie WC: Subdural empyema in Africans in Rhodesia. Neurosurgery 3:385-391, 1978

17. Glickstein JS, Chandra RK, Thompson JW: Intracranial complications of pediatric sinusitis. Otolaryngol Head Neck Surg 134:733-736, 2006

18. Go C, Bernstein JM, de Jong AL, Sulek M, Friedman EM: Intracranial complications of acute mastoiditis. Int J Pediatr Otorhinolaryngol 52:143-148, 2000

19. Hakim HE, Malik AC, Aronyk K, Ledi E, Bhargava R: The prevalence of intracranial complications in pediatric frontal sinusitis. Int J Pediatr Otorhinolaryngol 70:1383-1387, 2006

20. Herrmann BW, Chung JC, Eisenbeis JF, Forsen JW Jr: Intracranial complications of pediatric frontal rhinosinusitis. Am J Rhinol 20:320-324, 2006

21. Hlavin ML, Kaminski HJ, Fenstermaker RA, White RJ: Intracranial suppuration: a modern decade of postoperative subdural empyema and epidural abscess. Neurosurgery 34:974-981, 1994 
22. Hoyt DJ, Fisher SR: Otolaryngologic management of patients with subdural empyema. Laryngoscope 101:20-24, 1991

23. Kombogiorgas D, Seth R, Athwal R, Modha J, Singh J: Suppurative intracranial complications of sinusitis in adolescence. Single institute experience and review of literature. Br J Neurosurg 21:603-609, 2007

24. Kristo A, Uhari M: Timing of rhinosinusitis complications in children. Pediatr Infect Dis J 28:769-771, 2009

25. Legrand M, Roujeau T, Meyer P, Carli P, Orliaguet G, Blanot S: Paediatric intracranial empyema: differences according to age. Eur J Pediatr 168:1235-1241, 2009

26. Leotta N, Chaseling R, Duncan G, Isaacs D: Intracranial suppuration. J Paediatr Child Health 41:508-512, 2005

27. Madhugiri VS, Sastri BV, Bhagavatula ID, Sampath S, Chandramouli BA, Pandey P: Posterior fossa subdural empyema in children-management and outcome. Childs Nerv Syst 27:137-144, 2011

28. McIntyre PB, Lavercombe PS, Kemp RJ, McCormack JG: Subdural and epidural empyema: diagnostic and therapeutic problems. Med J Aust 154:653-657, 1991

29. Migirov L, Duvdevani S, Kronenberg J: Otogenic intracranial complications: a review of 28 cases. Acta Otolaryngol 125:819-822, 2005

30. Nathoo N, Nadvi SS, Royston D, van Dellen JR, Rana M, Narotam PK, et al: Cerebral blood flow changes in rhinogenic subdural empyema and the role of hyperaemia in brain swelling. East Afr Med J 77:359-363, 2000

31. Nathoo N, Nadvi SS, van Dellen JR: Cranial extradural empyema in the era of computed tomography: a review of 82 cases. Neurosurgery 44:748-754, 1999

32. Nathoo N, Nadvi SS, van Dellen JR, Gouws E: Intracranial subdural empyemas in the era of computed tomography: a review of 699 cases. Neurosurgery 44:529-536, 1999

33. Nunez DA: Presentation of rhinosinugenic intracranial abscesses. Rhinology 29:99-103, 1991

34. Ong YK, Tan HK: Suppurative intracranial complications of sinusitis in children. Int J Pediatr Otorhinolaryngol 66:49, 2002

35. Orlov Iu A, Sarmiento O: [Otogenic and rhinogenic brain abscesses in children.] Vestn Otorinolaringol 4:27-30, 1990 (Russian)

36. Osman Farah J, Kandasamy J, May P, Buxton N, Mallucci C: Subdural empyema secondary to sinus infection in children. Childs Nerv Syst 25:199-205, 2009

37. Oxford LE, McClay J: Complications of acute sinusitis in children. Otolaryngol Head Neck Surg 133:32-37, 2005

38. Passeron H, Sidy Ka A, Diakhaté I, Imbert P: [Intracranial suppurations of otorhinolaryngological origin in children in Senegal.] Arch Pediatr 17:132-140, 2010 (Fr)

39. Pathak A, Sharma BS, Mathuriya SN, Khosla VK, Khandelwal N, Kak VK: Controversies in the management of subdural empyema. A study of 41 cases with review of literature. Acta Neurochir (Wien) 102:25-32, 1990

40. Pattisapu JV, Parent AD: Subdural empyemas in children. Pediatr Neurosci 13:251-254, 1987

41. Quraishi H, Zevallos JP: Subdural empyema as a complication of sinusitis in the pediatric population. Int J Pediatr Otorhinolaryngol 70:1581-1586, 2006

42. Rosenfeld EA, Rowley AH: Infectious intracranial complications of sinusitis, other than meningitis, in children: 12-year review. Clin Infect Dis 18:750-754, 1994

43. Salunke PS, Malik V, Kovai P, Mukherjee KK: Falcotento- rial subdural empyema: analysis of 10 cases. Acta Neurochir (Wien) 153:164-170, 2011

44. Seven H, Coskun BU, Calis AB, Sayin I, Turgut S: Intracranial abscesses associated with chronic suppurative otitis media. Eur Arch Otorhinolaryngol 262:847-851, 2005

45. Shokunbi MT, Malomo AO: Intracranial subdural empyema: burr hole exploration for diagnosis and treatment. Afr J Med Med Sci 22:9-12, 1993

46. Sichizya K, Fieggen G, Taylor A, Peter J: Brain abscessesthe Groote Schuur experience, 1993-2003. S Afr J Surg 43: 79-82, 2005

47. Singh B, Van Dellen J, Ramjettan S, Maharaj TJ: Sinogenic intracranial complications. J Laryngol Otol 109:945-950, 1995

48. Skelton R, Maixner W, Isaacs D: Sinusitis-induced subdural empyema. Arch Dis Child 67:1478-1480, 1992

49. Small M, Dale BA: Intracranial suppuration 1968-1982-a 15 year review. Clin Otolaryngol Allied Sci 9:315-321, 1984

50. Smith HP, Hendrick EB: Subdural empyema and epidural abscess in children. J Neurosurg 58:392-397, 1983

51. Sultész M, Csákányi Z, Majoros T, Farkas Z, Katona G: Acute bacterial rhinosinusitis and its complications in our pediatric otolaryngological department between 1997 and 2006. Int J Pediatr Otorhinolaryngol 73:1507-1512, 2009

52. Szmeja Z, Kruk-Zagajewska A, Kulczyński B, Szyfter W, Soboczyński R: [Otogenic brain abscesses in children.] Otolaryngol Pol 45:405-410, 1991 (Polish)

53. Tewari MK, Sharma RR, Shiv VK, Lad SD: Spectrum of intracranial subdural empyemas in a series of 45 patients: current surgical options and outcome. Neurol India 52:346-349, 2004

54. Tsai BY, Lin KL, Lin TY, Chiu CH, Lee WJ, Hsia SH, et al: Pott's puffy tumor in children. Childs Nerv Syst 26:53-60, 2010

55. United States Census Bureau: Population Estimates. (http:// www.census.gov/popest/estimates.html) [Accessed March 30, 2011]

56. Venkatesh MS, Pandey P, Devi BI, Khanapure K, Satish S, Sampath S, et al: Pediatric infratentorial subdural empyema: analysis of 14 cases. J Neurosurg 105 (5 Suppl):370-377, 2006

57. Wackym PA, Canalis RF, Feuerman T: Subdural empyema of otorhinological origin. J Laryngol Otol 104:118-122, 1990

58. Wanna GB, Dharamsi LM, Moss JR, Bennett ML, Thompson RC, Haynes DS: Contemporary management of intracranial complications of otitis media. Otol Neurotol 31:111-117, 2010

59. Wong AM, Zimmerman RA, Simon EM, Pollock AN, Bilaniuk LT: Diffusion-weighted MR imaging of subdural empyemas in children. AJNR Am J Neuroradiol 25:1016-1021, 2004

60. Wu TJ, Chiu NC, Huang FY: Subdural empyema in children20-year experience in a medical center. J Microbiol Immunol Infect 41:62-67, 2008

61. Yende AK, Mohanty S: Massive falx cerebri empyema. Neurol India 51:65-66, 2003

Manuscript submitted November 5, 2010.

Accepted March 24, 2011.

Address correspondence to: Joseph H. Piatt Jr., M.D., Division of Neurosurgery, Nemours/Alfred I. duPont Hospital for Children, 1600 Rockland Road, Wilmington, Delaware 19803.email: jpiatt@ nemours.org. 